\title{
Pengaruh Kegiatan Menempel Gambar Teknik Mozaik Terhadap Perkembangan Motorik Halus Pada Anak Usia Prasekolah Di RA Nurul Huda
}

\section{The Influence of Images of Mozaik Engineering Image Activities on the Development of Fine Motorcycle in Pre-School Age in RA Nurul Huda Mojoroto Kediri}

\author{
Susana Alorida Moka*, Nara Lintan Mega Puspita, Halimatus Saidah \\ *Program Studi Ilmu Kebidanan D.IV, Fakultas Ilmu Kesehatan, Universitas Kadiri \\ Kediri JL, Selomangleng No. 1 Kediri, Telp.(0354)775074/771846 \\ Email: *susanmoka84@gmailcom
}

\begin{abstract}
ABSTRAK
Perkembangan motorik halus adalah proses tumbuh kembang kemampuan gerak seorang anak, kemampuan menggerakan otot-otot kecil yang berkembang sejalan dengan kematangan saraf, otot anak ataupun kemampuan kognitifnya dan setiap gerakan sesederhana apapun merupakan hasil pola interaksi yang kompleks dari berbagai bagian dan sistem dalam tubuh yang dikontrol oleh otak. Motorik merupakan perkembangan pengendalian gerakan tubuh manusia melalui susunan saraf, otot, dan otak. Perkembangan Motorik halus anak dapat distimulasi dengan pemberian kegiatan menempel teknik mozaik yang dapat melatih gerakan otot- otot kecil pada anak secara bertahap dan teratur. Penelitian ini bertujuan untuk meningkatkan perkembangan motorik halus anak usia prasekolah melalui kegiatan menempel teknik mozaik di RA Nurul Huda Mojoroto-Kota Kediri Tahun 2020.

Rancangan penelitian yang digunakan adalah penelitian preeksperimental dengan sampel sebanyak 16 responden, dengan menggunakan teknik random sampling. Instrumen yang digunakan adalah SOP dan lembar observasi checklist angket performance. Data dianalisa dengan SPSS dengan uji Wilcoxon Rank Test

Hasil penelitian menunjukkan bhawa sebelum diberikan kegiatan teknik mozaik $50.0 \%$ memiliki perkembangan motoric halus dalam kategori belum mampu, sesudah diberikan kegiatan menempel teknik mozaik $93.8 \%$ responden memiliki perkembangan motorik halus dalam kategori mampu. Hasil uji Wilcoxon rank test didapatkan $\rho$ value: 0,02 yang berarti $\mathrm{H} 0$ ditolak dan $\mathrm{H}_{1}$ diterima, artinya ada pengaruh terhadap perkembangan motorik halus anak usia prasekolah di RA Nurul Huda Mojoroto-Kota Kediri Tahun 2020.

Berdasarkan hasil penelitian diharapkan dapat meningkatkan perhatian dari orangtua ataupun pendidik dalam menstimulasi perkembangan motorik halus pada anak salah satunya dengan memberikan kegiatan menempel teknik mozaik.
\end{abstract}

Kata Kunci: Perkembangan motorik halus, Teknik Mozaik, Anak Usia Prasekolah 


\begin{abstract}
Motoric development is the process of growth and development of a child's ability to move, the ability to move small muschles that developein line with the maturnity of nerves, the child's muscles or cognitive abilities and any movement as simple as anything is a result of complex interaction patterns of various, parts, and systems in the body that are controlled by the brain. Motoric is the development of controlling the movement of the human body through the arrangement of nerves, muscles, and brain. Fine Motoric development of children can be stimulated by giving activities to stick to mozai techniques that can train the small muscles in children gradually and regularly. This research aims to improve the fine motoric development of preschoolers through attaching mosaic techniques in RA Nurul Huda Mojoroto-Kediri City in 2020.

The research design used was a pre-experimental study, the sample studied was 16 respondents, using random sampling techniques. The instrument used were standar operating procedure (SOP) and questionnaire performance checklist observation sheet. Data were analyzed by SPSS using Wilcoxon Rank Test.

The results showed that before being given the mosaic technique $50.0 \%$ had fine motoric developmentin the category of not being able to, after being given activities attached to the mosaic technique $93.8 \%$ of respondents had the development of fine motoric in the capable category. Wilcoxon rank test results obtained $\rho$ value: 0.02 which means $\mathrm{H} 0$ is rejected and $\mathrm{H} 1$ is accepted, meaning that there is an influence on the fine motor developmentof preschool children in RA Nurul Huda Mojoroto-Kediri City in 2020.

Based on the research results are expected to increase the attention of parents or educators in stimulating fine motoric development in children one of them by giving activities to stick to the mosaic technique.
\end{abstract}

Keywords: Fine Motoric Development, MosaicTechnique, Preschool Age Childreen

\title{
PENDAHULUAN
}

Pendidikan anak usia dini pada jalur pendidikan formal Taman Kanakkanak (TK) berada dalam rentang usia 4-6 tahun, dimana anak dengan kisaran usia tersebut merupakan anak yang sedang mengalami pertumbuhan serta perkembangan yang sangat pesat. Aspek-aspek perkembangan yang perlu diperhatikan pada anak usia dini diantaranya aspek nilai-nilai agama dan moral, kognitif, bahasa, sosial emosional, dan fisik motoric. Perkembangan motorik adalah suatu proses yang berkesinambungan dalam berkembangnya kemampuan gerak anak dari pola interaksinya yang kompleks yakni hasil dari system kerja dalam tubuh yang dikontrol oleh otak.

Data menurut Departemen RI tahun 2017 mencatat bahwa anak di indonesia banyak yang mengalami gangguan perkembangan dalam pendengaran, sosialisasi, keterlambatan dalam berbicara dan keterlambatan dalam perkembangan motorik halus sebanyak $20 \%$ atau setara 0,2 juta anak. Menurut data Depkes RI, ada $18 \%$ balita yang mengalami gangguan pada perkembangan motorik mereka, baik motorik halus maupun motoric kasar. 
Berdasarkan data Departemen RI tahun 2017, Provinsi Jawa Timur banyak kasus anak dan remaja dengan gangguan pada motorik halus dan kasar sebanyak 155 kasus.

Dampak dari lambatnya perkembangan motorik halus anak terdiri atas 2 yakni, dampak mikro dan dampak makro. Dampak mikro berupa kemunduran perkembangan akan menghambat perkembangan yang lain yang dikemudian hari akan mengganggu perkembangan kognitif anak maupun fisik, seperti pergerakan jari-jemari tangan, kemampuan pergelangan tangan, dan kemampuan koordinasi mata dengan tangan, dan pergerakan jari-jemari tangan dalam melakukan suatu kegiatan, baik menempel ataupun menggambar. (Yusuf, 2017).

Solusi utama dalam pencegahan dan penanganan melambatnya kemampuan motorik halus dengan adanya kegiatan menempel teknik mozaik pada anak yakni, dengan adanya teknik mozaik ini diharapkan bisa menjadi pedoman bagi tenaga pendidik dalam membimbing dengan mempertimbangkan latihan perkembangan yang tepat serta menarik, bagaimana membantu anak menempel yang tepat, sisi apa yang perlu dikembangkan dan dibantu, dan penentuan jenis latihan perkembangan yang tepat dan aman bagi anak agar dapat meningkatkan kemampuan motorik halusnya. Solusi bagi orangtua pun perlu memberikan rangsangan melalui latihan dirumah dengan menggunakan teknik mozaik karena peran orangtua sangat penting juga, yang dapat menstimulasi anak secara cepat dan tanggap dalam melatih kemampuan motorik halusnya secara bertahap, latihan kemampuan sosial seperti menempel bersama dengan orangtua atau teman sebaya, karena pada umumnya anak lebih suka untuk melakukan segala sesuatu sendiri dan mandiri diluar/pun didalam rumah, oleh karena itu perlu adanya koordinasi baik pula dari orangtua untuk dapat memberikan ruang dan waktu bagi anak untuk dapat melakukan kegiatan yang dapat melatih motorik halusnya dengan selalu menyediakan barangbarang/wadah yang bisa digunakan untuk menunjang kegiatan anak seperti; menempel teknik mozaik. (Rini, 2018)

Dari rumusan masalah diatas maka tujuan dalam penelitian ini adalah untuk mengetahui Pengaruh kegiatan menempel gambar teknik mozaik terhadap perkembangan motorik halus pada anak di RA-Nurul Huda, Mojoroto- Kota Kediri. Secara teoritis, penelitian ini menambah pengetahuan, pengalaman, dan wawasan serta referensi kepustakaan dan ilmu pengetahuan kebidanan tentang motorik halus anak, khususnya pengaruh kegiatan menempel gambar teknik mozaik terhadap perkembangan motorik halus pada anak di RA-Nurul Huda Mojoroto- Kota Kediri.

\section{METODE}

Rancangan penelitian untuk pelaksanaan penelitian ini berdasarkan lingkup penelitian termasuk penelitian inferensial. Berdasarkan desain penelitian termasuk penelitian Pre-eksperimen design yaitu melakukan penelitian sekaligus memberikan perlakuan dan mengevaluasi perlakuan tersebut. 
Penelitian ini menggunakan metode One group pretest-posttest design yaitu rancangan dengan memberikan pretest (pengamatan awal) dengan mengukur tingkat respon motorik sebelum diberikan intervensi atau perlakuan. Setelah diberikan perlakuan kemudian dilakukan posttest (pengamatan akhir). dalam penelitian ini besar sampel yang diambil sebanyak 16 anak.

Pengambilan sampel penelitian ini dilakukan dengan teknik random sampling yaitu teknik pengambilan sampel secara acak dengan menggunakan rumus federrer. Analisa data penelitian ini menggunakan uji Wilcoxon rank test.

\section{HASIL DAN PEMBAHASAN}

Tabel 1 Perkembangan Motorik Halus Anak Usia Prasekolah sebelum diberikan kegiatan menempel teknik mozaik

\begin{tabular}{ccc}
\hline $\begin{array}{c}\text { Perkembangan Motorik Halus } \\
\text { Sebelum Diberikan Kegiatan } \\
\text { Menempel Teknik Mozaik }\end{array}$ & Frequency & Percent \\
\hline Tidak Mampu & 1 & 6.3 \\
Belum Mampu & 8 & 50.0 \\
Mampu & 7 & 43.8 \\
Total & 16 & $100.0 \mathrm{~m}$ \\
\hline
\end{tabular}

Sumber: Data Primer, 2020

Tabel 1 menunjukkan Hampir setengahnya anak usia prasekolah yaitu sebanyak 8 (50,0\%) sebelum diberikan kegiatan menempel teknik mozaik termasuk dalam kategori perkembagan belum mampu, anak usia prasekolah dengan perkembangan mampu yaitu $7(43,8 \%)$, dan $1(6,3 \%)$ anak usia prasekolah dengan perkembangan tidak mampu

Tabel 2 Perkembangan Motorik Halus Anak Usia Prasekolah sesudah diberikan kegiatan menempel teknik mozaik

Perkembangan Motorik Halus

Sesudah Diberikan Kegiatan Frequency Percent

Menempel Teknik Mozaik

\begin{tabular}{ccc}
\hline Belum Mampu & 1 & 6.3 \\
Mampu & 15 & 93.8 \\
Total & 16 & 100.0 \\
\hline
\end{tabular}

Tabel 2 Menunjukkan Hampir seluruhnya anak usia prasekolah setelah diberikan kegiatan menempel teknik mozaik perkembangannya dalam kategori mampu yaitu 15 (93,8\%), dan anak usia prasekolah dalam kategori belum mampu menjadi $1(6,3 \%)$. 
Tabel 3 Pengaruh Sebelum dan Sesudah diberikan Kegiatan Menempel Teknik Mozaik Terhadap Perkembangan Motorik Halus pada Anak Usia Prasekolah

\begin{tabular}{|c|c|c|c|c|c|c|c|c|}
\hline \multirow{3}{*}{$\begin{array}{c}\text { Perkembangan } \\
\text { Motorik Halus } \\
\text { Sebelum diberikan } \\
\text { Kegiatan Menempel } \\
\text { Teknik Mozaik }\end{array}$} & \multicolumn{6}{|c|}{$\begin{array}{c}\text { Perkembangan Motorik Halus } \\
\text { Sesudah diberikan Kegiatan } \\
\text { Menempel Teknik Mozaik }\end{array}$} & \multirow{2}{*}{\multicolumn{2}{|c|}{ Total }} \\
\hline & \multicolumn{2}{|c|}{$\begin{array}{l}\text { Tidak } \\
\text { Mampu }\end{array}$} & \multicolumn{2}{|c|}{$\begin{array}{l}\text { Belum } \\
\text { Mampu }\end{array}$} & \multicolumn{2}{|c|}{ Mampu } & & \\
\hline & $f$ & $\%$ & $\mathrm{~F}$ & $\%$ & $\mathrm{f}$ & $\%$ & $\mathrm{~F}$ & $\%$ \\
\hline Tidak Mampu & 0 & 0 & 0 & 0 & 0 & 0 & 0 & 0 \\
\hline Belum Mampu & 0 & 0 & 1 & 6.2 & 10 & 62.5 & 11 & 68.7 \\
\hline Mampu & 0 & 0 & 0 & 0 & 5 & 31.3 & 5 & 31.3 \\
\hline Total & 0 & 0 & 1 & 6.2 & 15 & 93.8 & 16 & 100 \\
\hline
\end{tabular}

Tabel 3 bahwa hasil penelitian menunjukan sebelum dberikan kegiatan menempel teknik mozaik terdapat 1 (6.2\%) responden yang masuk dalam kategori belum mampu, ada peningkatan perkembangan motorik halus pada keseluruhan 16 responden (100\%) sesudah diberikan kegiatan menempel teknik mozaik.

Dari hasil analisa melalui uji Wilcoxon rank test didapatkan negative rank: 0 , yang berarti tidak ada responden yang mengalami penurunan setelah diberikan perlakuan dengan kegiatan menempel teknik mozaik, nilai positive rank: 10 yang berarti ada 10 responden yang mengalami perubahan peningkatan kemampuan motoric halus setelah diberikan kegiatan menempel teknik mozaik. Nilai Ties. 6, yang berarti adanya 6 responden yang tidak mengalami perubahan setelah diberikan kegiatan menempel teknik mozaik yakni 1 responden yang memiliki kategori perkembangan motorik halus kategori belum mampu dan 15 responden dengan kategori perkembangan motorik halus mampu setelah diberikan kegiatan menempel teknik mozaik. Pada tabel statistik menunjukkan $\rho$ value: 0,02 dimana nilai $\rho<0,05$ yang berarti $\mathrm{H}_{0}$ ditolak dan $\mathrm{H}_{1}$ diterima, yang artinya ada pengaruh kegiatan menempel teknik mozaik terhadap perkembangan motorik halus anak usia prasekolah

\section{KESIMPULAN DAN SARAN}

Kesimpulan dari penelitian ini adalah ada pengaruh kegiatan menempel teknik mozaik terhadap perkembangan motorik halus anak usia prasekolah di RA Nurul Huda Mojoroto-Kota Kediri Tahun 2020. Dari hasil penelitian dapat disarankan untuk peneliti selanjutnya untuk dapat mengembangkan penelitian dengan menambahkan variable penelitian misalnya tentang faktor-faktor yang mempengaruhi perkembangan motorik halus anak usia prasekolah.

\section{UCAPAN TERIMA KASIH}

Ucapan terimakasih kepada kepala RA Nurul Huda Kota Kediri yang bersedia dijadikan tempat penelitian. Dekan Fakultas Ilmu Kesehatan, serta Dosen pembimbing ibu Nara Lintan Mega Puspita dan ibu Halimatus Sa'idah yang telah sabar dalam membimbing. 


\section{DAFTAR PUSTAKA}

Anggara Ista Putra. (2018). No Title (Vol. 3, Issue 32).

Affandi, Achmad. 2018. Pendidikan Dan Perkembangan Motorik. Jakarta: Uwais Inspirasi Indonesia

Bambang. Dkk.2008. Metode Pengembangan Fisik.Jakarta.Universitas Terbuka.

Co, K. L. (2018). Identifikasi Pengembangan Motorik Halus. No Title. 16.

Desti Dwi Lestari ,2013. Pengaruh Teknik Mozaik Pada Anak.

Ebbeck, M., Yim, H. Y. B., \& Warrier, S. (2019). Early Childhood Teachers' Views And Teaching Practices In Outdoor Play With Young Children In Singapore. Early Childhood Education Journal. Https://Doi.Org/10.1007/S10643-018-00924-2

Effi Kumala Sari. (2014). Peningkatan Perkembangan Motorik Halus Anak Melalui Kegiatan Kolase Dari Bahan Bekas Di Taman Kanak-Kanak Aisyiyah Simpang Iv Agam. Pesona Paud, 1(1), 1-11.

Elsera, F., \& Indotang, F. (2014). Program Studi S1 Keperawatan Fakultas Ilmu Kesehatan Universitas Muhammadiyah Surabaya 2014.

Igak Wardani, Dkk. 2007. Penelitian Tindakan Kelas. Jakarta: Universitas Terbuka.

Inter Bungin, Burhan. 2011. Metode Penelitian Kuantitatif. Jakarta: Kencana Prenada Media Group. Sujiono, Bambang. 2005. Metode Pengembangan Fisik. Jakarta: Universitas Terbuka.

Indraswari, L. (2013). Peningkatan Perkembangan Motorik Halus Anak Usia Dini Melalaui Kegiatan Mozaik Di Taman Kanak-Kanak Pembina Agam. Pesona Paud, 1(1), 1-13.

Intan Nursayyidah W, I. N. (2018). Pengaruh Kegiatan Mozaik Terhadap Kemampuan Motorik Halus Anak Usia 4-6 Tahun. "Ceria" Jurnal Program Studi Pendidikan Anak Usia Dini, 7(2), 12-25.

Istiqomah, L., \& Khotimah, N. (2017). Pengaruh Kegiatan Mozaik Terhadap Kemampuan Keterampilan Motorik Halus Pada Anak Kelompok B Di Tk Aisyiyah Bustanul Athfal 3 Surabaya. Jurnal Paud Teratai, 06(03).

Kunci, K., \& Mozaik, T. (2016). Kata Kunci : Motorik Halus, Tehnik Mozaik. 8, 7383.

Lynch, T. (2018). Physically Educated: Developing Children's Health And Wellbeing Through Movement And Motor Skills. In Health And Wellbeing In Childhood (Pp. 77-94). Cambridge University Press. Https://Doi.Org/10.1017/9781 